\title{
Cabin Layout Optimization Design and Ergonomics Evaluation
}

\author{
LIU Chengping ${ }^{12, a}$, WU $X^{1 *, b}$ and ZHAO Jingquan ${ }^{1, c}$ \\ ${ }^{1}$ School of Aeronautic Science and Engineering, Beijing University of Aeronautics and Astronautics, \\ Beijing, China \\ ${ }^{2}$ China Academy of Electronics and Information Technology, Beijing, China \\ aliuchengping@foxmail.com, be126126_19@126.com, czjq206@buaa.edu.cn
}

Keywords: layout optimization; genetic algorithm; cabin modeling; 3-D human analysis; ergonomics

\begin{abstract}
Special aircraft cabin layout optimization design was treated as an NP-complete (nondeterministic Polynomial time complete) problem. The empirical design was incapable to meet the developing requirement of the display and control system in modern aircraft cabin. After analysis of three typical cabin layout cases, several factors were found to need optimization in these cases. Therefore, the present study proposed an improved genetic algorithm based on human factors. An optimized cabin layout was carried out by setting the objective function and constraints. Besides, aiming at evaluating the cabin layout, JACK 3-D human analysis software was applied to calculate the operator's reach zone and view cone. This study could provide a technical reference for the cabin layout design of special aircraft.
\end{abstract}

\section{Introduction}

As an integral role of the information weapons and equipment in modern warfare, modern special aircraft performed various tasks, such as early warning detection, intelligence reconnaissance, communications relay, command and control, and battlefield management. Meanwhile, special aircraft was equipped with IFF (Identification Friend or Foe), navigation, electronic reconnaissance, confrontation optoelectronic and numerous other display and control systems [1]. On account of the appropriate layout of these display and control systems, designers usually applied certain design criteria and design experience to arrange various devices in certain positions. So that, the layout would meet the functional requirements of the task [2-3]. However, this layout approach was lack of consideration of human factors, such as escape route planning and operating comfort of operator [5-6]. Moreover, it might be difficult to evaluate the quality of cabin layout design precisely and quantitatively.

There were usually two approaches in the current layout design studies. One was to solve the layout problem only by mathematical models. The other one was to reasonably arrange these devices only by ergonomics principles of layout [2-10]. Even though Wang Y. L. proposed some improved genetic algorithm. Nevertheless the constraints were relatively simple, and application of the objective functions was limited to areas of ship, civil aircraft cabin and vehicle [7-9]. The display and control systems of special aircraft cabin had more complex and changeable requirements on layout. It was a serious problem to set forth a layout optimization algorithm for special aircraft cabin by combining accurate mathematical models with specialized expert technology [9-10]. In addition, the optimized case worked out by optimization algorithm still needed simulation and verification. Thus, a more considerate reference would be presented for the cabin optimized layout case [11]. In consequence, the present study integrated three-dimensional simulation software CATIA, ergonomic evaluation software JACK and algorithm software MATLAB. After modeling and simulating cabin layout cases, three typical cases were evaluated and analyzed according to relevant design standards [13]. Then an improved genetic algorithm based on HCI was used to work out optimized layout cases. Ultimately, an ergonomics evaluation system was built to assess and raise ergonomic cabin layout cases, which could provide technical basis for the improvement of the integrated performance and development of the layout cases for large special aircraft. 


\section{Cabin Layout Design Guidelines}

Certain basic principles of cabin layout should be followed including: a. integrated principle, all the factors which affected devices layout should be considered to achieve optimized case [12]; $b$. space utilization principle, since cabin space was relatively narrow, the space should be used effectively, so that relative activity area increased and space utilization was improved due to compact layout[12]; c. unblocked principle, the cabin devices layout should keep path unblocked to ensure a convenient access in cabin. Cabin layout should be reasonable without hindrance. Especially under emergency situations, reasonable evacuation distance should be guaranteed [12]; d. ergonomic principle, cabin devices layout should take the ergonomic requirements for device position into consideration. Scientific data should be applied to combine cabin layout design with human body size to improve the comfort of operating space [5, 13-14]. Three aspects of human, device and cabin environment were closely associated, so that the needs of operator in cabin to capacity should be satisfied. Besides, GJB2873-97 (ergonomic design guidelines for military equipment and facilities) [13] was with regard to the relevant military standard about cabin layout design. It provided specific standard for the size of display and control system, seat, exit passageway, maintenance space and other aspects in the layout optimization.

\section{Analysis of Typical Cabin Layout Cases}

As shown in fig. 1, CATIA was utilized to conduct three-dimensional digital model for the proposed three typical cabin layout cases. Considering the differences in a variety of factors, quantitative analysis and preliminary evaluation were carried out, as shown in Table 1 below.

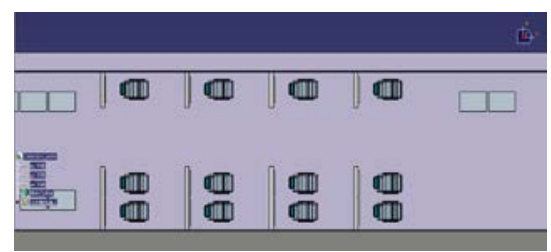

(a)case 1

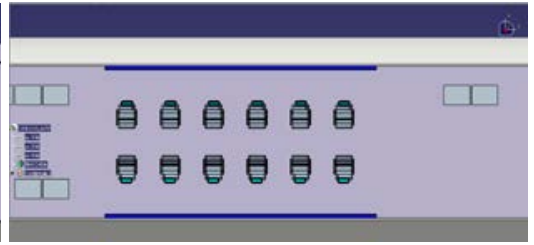

(b)case 2

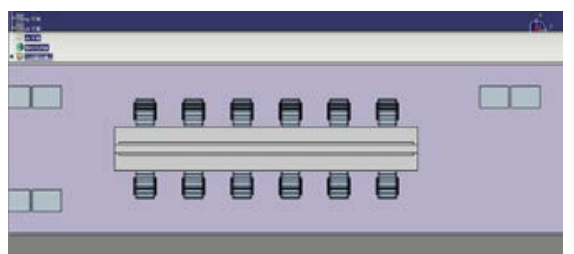

(c)case 3

Fig.1 Cabin layout cases

Table 1 Factor analysis of cabin layout cases

\begin{tabular}{c|cccccc}
\hline Layout case & display & orientation & path number & path width & display horizon & device spacing \\
\hline 1 & single screen & along direction & 1 & $1500[\mathrm{~mm}]$ & $606[\mathrm{~mm}]$ & $392[\mathrm{~mm}]$ \\
2 & large screen & sideways direction & 1 & $745[\mathrm{~mm}]$ & $1106[\mathrm{~mm}]$ & $762[\mathrm{~mm}]$ \\
3 & large screen & sideways direction & 2 & $992[\mathrm{~mm}]$ & $372[\mathrm{~mm}]$ & $784[\mathrm{~mm}]$ \\
\hline
\end{tabular}

Orientation. The cases involved two different orientation: along direction and sideways direction separately. Different orientation would result in the difference in operator's overload direction.

Active path. The cases referred to two kinds of reserved path: a wide path in the middle of the cabin and two narrow paths on both sides of the cabin.

Escape route. Three cases had their own differences. Aiming at different path number and width, the present study decided to calculate actual channel width to evaluate escape route.

Display horizon. There were three kinds of display horizon, which were long distance (about $1100 \mathrm{~mm}$ ), moderate distance (about $600 \mathrm{~mm}$ ) and close (about $300 \mathrm{~mm}$ ). Among which, the horizon of $372 \mathrm{~mm}$ in case 3 was close to the minimum limit. The other two cases both met the requirements in GJB 2873-97: “5.2.1.4.12 the minimum horizon: except for CRT display and collimation display, the effective horizon should not be less than $330 \mathrm{~mm}$ and preferably not be less than $510 \mathrm{~mm}$.” [13]

Device spacing. Moderate distance (about $750 \mathrm{~mm}$ ) and close (about $400 \mathrm{~mm}$ ) were involved in the cases. If device spacing was too close, neighboring operators would be uncomfortable in some degree. 
On the contrary, if device spacing was too far, the communication between operators would be more difficult.

\section{Cabin Layout Optimized Design}

To solve the cabin layout problem, firstly, basic constraints which affected layout design should be carefully analyzed to set up the mathematic model for describing cabin layout. Secondly, NSGA- II algorithm with elitist strategy based on $\mathrm{HCI}$ (shown in fig. 2) was chosen to calculate the model and find out the optimized layout case.

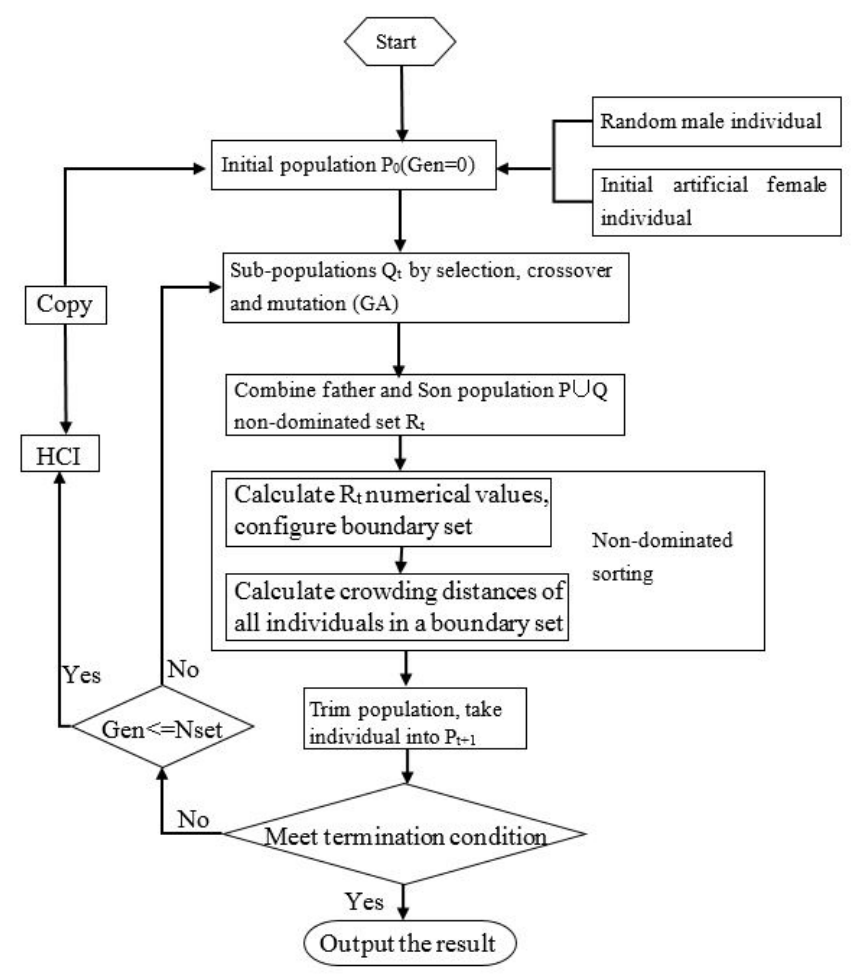

Fig.2 Flow chart of improved genetic algorithm based on man-machine interaction

\section{A. Mathematical Modeling of Cabin Layout Optimization Design.}

The characteristic of cabin layout was analyzed. The cabin was set as layout container. And cabin attachments were set as objects to be arranged, such as display and control device, as well as seat. The cabin attachments were simplified into rectangular to establish the mathematical model of cabin layout.

Setting Variable. The purpose of layout design was to determine the reasonable space position of each attachment. So the variable was set to be the two-dimensional position variable of the attachments, that is:

$$
X=\left\{X_{1}, X_{2}, \ldots, X_{n}\right\}=\left\{\left(x_{1}, y_{1}\right),\left(x_{2}, y_{2}\right), \ldots,\left(x_{n}, y_{n}\right)\right\} .
$$

In Eq.(1), ${ }^{x_{n}, y_{n}}$ were ${ }^{x, y}$ direction coordinate of attachment $\mathrm{n} . \mathrm{n}$ was the number of attachment.

Setting Objective Function. According to the aforementioned factors of layout, the four objective function of layout optimization model could select interference distance, function allocation, active space and escape route.

There should be no interference among a plenty of attachments in cabin. Therefore, the objective function $^{F_{1}(x, y)}$ was used to describe the interference distance:

$$
F_{1}(x, y)=\left\{\max \left(\sum \sum D\left(X_{i j}\right)\right) \mid D\left(X_{i j}\right)=\left(x_{i}-x_{j}\right)^{2}+\left(y_{i}-y_{j}\right)^{2}, \mathrm{ij} \in[1, m], i \neq j\right\} .
$$


In Eq.(2), ${ }^{x_{i}, x_{j}, y_{i}, y_{j}}$ represented the specific positional parameters of attachments with requirements for interference distance. $m$ was the number.

The display and control devices, which had the same requirement of function and task, were supposed to be arranged closely. The objective function $F_{2}(x, y)$ describes the functional distance:

$$
F_{2}(x, y)=\left\{\max \left(\sum \eta_{i} \sum\left[D\left(X_{i j}\right) \xi_{i j}^{-1}\right]\right) \mid D\left(X_{i j}\right)=\left(x_{i}-x_{j}\right)^{2}+\left(y_{i}-y_{j}\right)^{2}, \mathrm{ij} \in[0, \mathrm{n}], \eta_{i} \xi_{i j} \in[0,1], i \neq j\right\} .
$$

In Eq.(3), $\eta_{i}$ stood for the task priority level and task-related degree of the display and control device. And $\xi_{i j}$ represented consistency degree in the function and task type of display and control device in cabin.

Some cabin position and space were the central region for operator's activity. To maximize the region area, the objective function $F_{3}(x, y)$ was applied to account for this active space:

$$
F_{3}(x, y)=\left\{\max \left(\sum \omega_{i} D_{a}\left(X_{i}\right)\right) \mid D_{a}\left(X_{i}\right)=\left(x_{i}-x_{a}\right)^{2}+\left(y_{i}-y_{a}\right)^{2}, \mathrm{i} \in[1, \mathrm{n}], \omega_{i} \in[0,1]\right\} .
$$

In Eq.(4), $\omega_{i}$ was the weight coefficients of the region related to the attachment, so $\sum_{i=1}^{n} \omega_{i}=1$. And $X_{a}$ was the position parameter of the central activity region.

Taking the cabin escape path problem into account, the total path between each display control device and cabin door should be the shortest. Thereby, the objective function $F_{4}(x, y)$ was used to describe this escape route:

$$
F_{4}(x, y)=\left\{\min \left(\sum D_{d}\left(X_{i}\right)\right) \mid D_{d}\left(X_{i}\right)=\left(x_{i}-x_{d}\right)^{2}+\left(y_{i}-y_{d}\right)^{2}, \mathrm{i} \in[1, \mathrm{n}]\right\} \text {. }
$$

In Eq.(5), $X_{d}$ represented the position parameter of the cabin exit.

In short, the objective function in the mathematical model of cabin layout optimization was:

$$
F(x, y)=\bigcup \mu_{i} F_{i}(x, y), i=1,2,3,4 .
$$

In Eq.(6), $\mu_{i}$ stood for the weight of the objective function.

Setting Constrains. Considering the above factors of layout design, four kinds of constrains were mainly quantified:

1) Layout container constrain. It was the cabin boundary that could not be exceeded. And the positional relationship between two attachments also had requirement about distance. Therefore, constrain condition $C_{1}(x, y)$ can be established:

$$
C_{1}(x, y)=\left\{\forall X_{i}, \exists D\left(X_{i j}\right)=\left(x_{i}-x_{j}\right)^{2}+\left(y_{i}-y_{j}\right)^{2} \text {, s.t. } X_{i} \subset \overline{\left(s_{i}, q_{i}\right)} \cup(L, W), D\left(X_{i j}\right) \subset\left(d_{x i j}, d_{y i j}\right)\right\} .
$$

In Eq.(7), $\left(s_{i}, q_{i}\right)$ represented the rectangular space formed by length and width of each attachment. $(L, W)$ stood for the rectangular space formed by that of cabin container. $d_{x i j}, d_{y i j}$ were the distance requirements between attachments on the $x, y$ direction.

2) Non-interference among attachments. Intersect was prohibited in layout position of each attachment. And the constrain condition $C_{2}(x, y)$ was built:

$$
C_{2}(x, y)=\left\{\forall X_{i}, Y_{i}, \exists \Omega\left(X_{i j}\right)=\left(a b s\left(x_{i}-x_{j}\right), a b s\left(y_{i}-y_{j}\right)\right) \text {, s.t. } \Omega\left(X_{i j}\right) \supset\left(\left(s_{i}+s_{j}\right) / 2,\left(q_{i}+q_{j}\right) / 2\right)\right\} .
$$


The above $\left(\left(s_{i}+s_{j}\right) / 2,\left(q_{i}+q_{j}\right) / 2\right)$ represented the interference requirements of length and width of each attachment on the $x, y$ direction.

3) Access door. In order to ensure that all attachments did not conflict with the access door, the basic space of the access door could be considered as an attachment. Thus the constrain condition $C_{3}(x, y)$ was obtained:

$$
C_{3}(x, y)=\left\{\forall X_{i}, \exists \Omega\left(X_{i d}\right)=\left(a b s\left(x_{i}-x_{d}\right), a b s\left(y_{i}-y_{d}\right)\right), \text { s.t. } \Omega\left(X_{i j}\right) \supset\left(\left(s_{i}+L_{d}\right) / 2,\left(q_{i}+W_{d}\right) / 2\right)\right\} .
$$

The above $\left(x_{d}, y_{d}\right)$ was the position parameter of the access door. $L_{d}, W_{d}$ stood for the length and width of the door. $\left(\left(s_{i}+L_{d}\right) / 2,\left(q_{i}+W_{d}\right) / 2\right)$ represented the interference requirements of the attachment and access door's own length and width on the $x, y$ direction.

4) Maintainability of attachment. The distance between attachments and the distance between attachment and cabin boundary should be retained for maintenance operations. The space requirement mainly referred to the $x$ direction. Meanwhile, considering the path width for activities in cabin, the activity path should be retained between attachments. This space requirement mainly depended on the $y$ direction. The condition $C_{4}(x, y)$ could be established on the basis of the above two constraints:

$$
C_{4}(x, y)=\left\{\forall X_{i}, X_{j}, \exists \Omega\left(X_{i j}\right)=\left(a b s\left(x_{i}-x_{j}\right), a b s\left(y_{i}-y_{j}\right)\right), \text { s.t. } \Omega\left(X_{i j}\right) \supset\left(u_{i}, v_{i}\right)\right\} .
$$

In Eq.(10), $u_{i}$ referred to the distance requirement of maintainability space on the $x$ direction. And $v_{i}$ was the distance requirement of path width on the $y$ direction.

As a result, in the mathematical modeling of cabin layout optimization, the constraints could be expressed as follows. And the final constraints must satisfy the constraints for all sub-criteria:

$$
C(x, y)=\cap C_{i}(x, y), i=1,2,3,4 .
$$

\section{B. Model Calculation Based on Genetic Algorithm.}

According to the established mathematical model, the improved genetic algorithm NSGA- II based on HCI was used. The formula calculator and Matlab programming were applied on the Isight platform.

In the above cabin layout cases, the cabin door located on the left, while the cabin activity region located on the right side. Moreover, the display and control device and seat could be abstracted as a whole rectangle. Thereby the various parameters of the mathematical model were set as follows:

$$
\left\{\begin{array}{l}
n=12, m=12, X_{a}=(9.17,2), X_{d}=(0,2), s_{i}=1, q_{i}=0.9, \\
L=9.17, W=4, L_{d}=0.6, W_{d}=3, u_{i}=0.4, v_{i}=0.6
\end{array}\right\} .
$$

The population size was set as 20 , the genetic algebra was set as 200 and the crossover and mutation probability was set as 0.9 . Then the convergence trend of the objective function was shown in fig. 3. The calculation process stopped after 4001 times and resulted in the optimized solution as follows:

$$
X=\left\{X_{1}, X_{2}, \ldots, X_{n}\right\}=\left\{\begin{array}{l}
(576,333),(348,66),(545,88),(243,76),(685,76),(141,76), \\
(356,245),(678,335),(244,330),(796,68),(140,303),(465,302)
\end{array}\right\} .
$$

The result was approximately the same as the layout in case 2. Twelve display and control devices were divided into two rows in the Y-axis direction. And each row contained evenly six display and control devices. The optimized case maximized the distance between display and control devices, and 
reserved a certain path region in the center of cabin, which was convenient for the operators to act and communicate. The optimized result shortened the distance between seat and display screen compared to case 2 . As a result, the width of active path increased effectively, which leading to a more conducive way to escape.
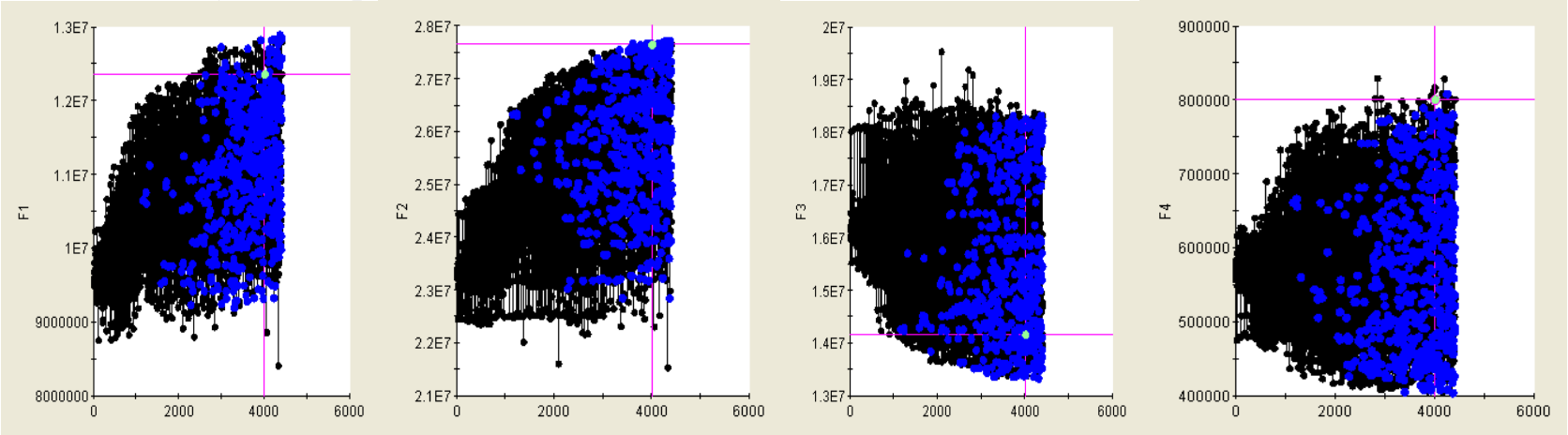

Fig.3 Convergent tendency of objective function 1, 2, 3, 4

\section{Ergonomics Evaluation of Cabin Layout}

\section{A. Reach Zone Analysis of Cabin Layout.}

Referring to GJB36A-2008, a pilot body model was established based on body size data of different percentage [14]. The reach zone analysis of cabin layout concentrated on the pilot body model of the 50th percentile. The operator's comfortable area and reachable area of both hands were analyzed and evaluated for three different cabin layout cases.

The reach envelop was shown in fig. 4. For the case 1 of cabin layout, the distance between the seat and the display was suitable and approximate $610 \mathrm{~mm}$. For case 2, the seat was the most far away from the display, approximately $1100 \mathrm{~mm}$. The distance in case 3 was the smallest and only $380 \mathrm{~mm}$. Noted that in case 3, the space for operator's knees between the seat and the display was insufficient.

According to the above reach zone analysis on cabin layout, the ergonomics evaluation results based on JACK found that the human-computer interaction (HCI) devices by the seats were in the operator's comfortable area in all three cabin layout cases. Therefore, the operation task, completed by keyboard, mouse and tablet with operator seated, would meet the ergonomics requirement. However, the sight distances were not appropriate in all three cases. Although the $1100 \mathrm{~mm}$ long distance from the device (case 2) provided the operator with an ample active space, the human-computer interaction on the display screen exceeded the reachable area, , caused inconvenience of the operator to some extent. Moreover, the $380 \mathrm{~mm}$ close distance (case 3) met the interactive reachable requirement, nevertheless there was insufficient room for operator's knees. On the contrary, the $610 \mathrm{~mm}$ moderate distance (case 1) showed well functional reachable and provided abundant active space. Besides, this distance also met the requirements of GJB2873 regarding recommended vision field.

\section{B. View Cone Analysis of Cabin Layout.}

The view cone analysis of cabin layout was similar to the foregoing reach zone test. The present study chose maximum static sight ( $35^{\circ}$ cone) and best sight ( $15^{\circ}$ cone) as study indices. The specific view cone analysis of operator was shown in fig. 5 .

In accordance with the view cone test of cabin layout, the ergonomic evaluation results by JACK software indicated that for the operator, with the increase of sight distance, the chance of display screen in maximum static sight would be larger. For the $1100 \mathrm{~mm}$ long distance, the display screen was almost within the region of maximum static sight. The operator did not need to pay head movement efforts to obtain the information on the display. However, the increase in sight distance had negative impact on information readability. Therefore, certain compensation on the character size would help the operator obtain information accurately and timely. 


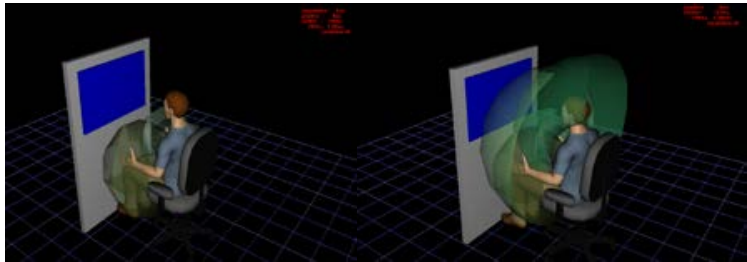

(a) Case 1

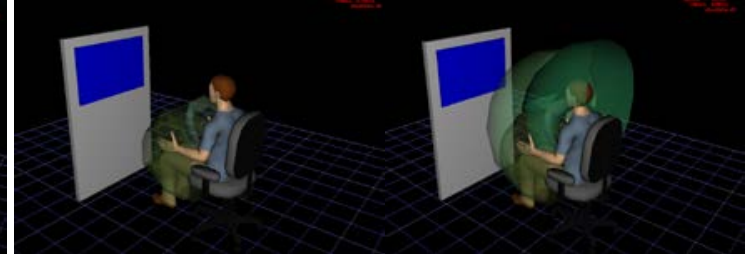

(b) Case 2

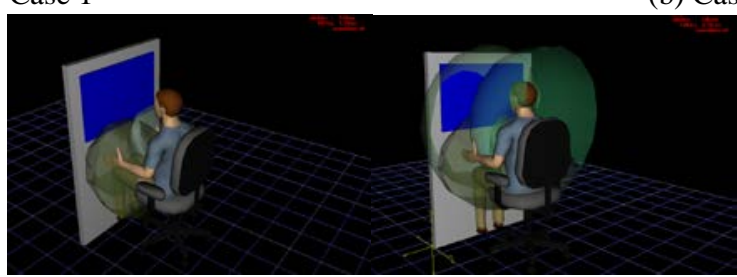

(c) Case 3

Fig.4 Comfortable area (left) and reachable area (right) of both hands

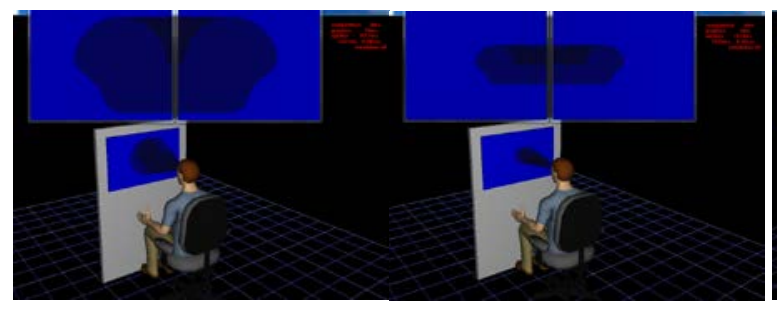

(a) Case 1

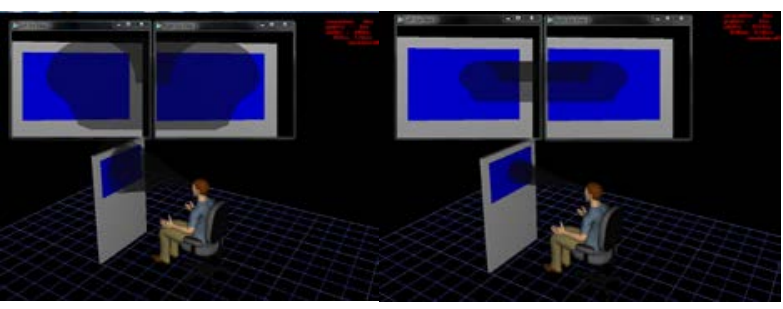

(b) Case 2

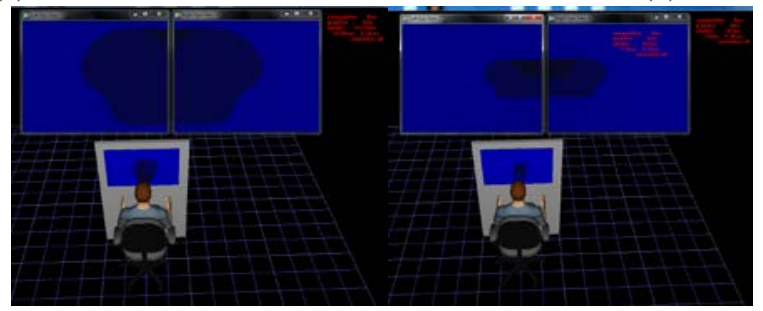

(c) Case 3

Fig.5 Maximum static sight (left) and best sight (right) with the first perspective

\section{Summary}

1) The basic principles, constraints and related standards of cabin layout design were summarized and proposed, which provided a theoretical basis for the comparison and optimization of the special aircraft cabin layout.

2) Focused on the optimization of cabin layout, an improved genetic algorithm model based on HCI was carried out, and an improved layout case of the special aircraft cabin was figured out by this model.

3) A simulation evaluation method for cabin ergonomics design was established using Jack three-dimensional body analysis software to assess operator's reach zone and view cone for each cabin layout case.

\section{References}

[1] C Cao. Devepments of AEW System for 70 Years. Journal of CAEIT Vol. 02 (2015), p. 113-118.

[2] I B Abbasov, V O V'iacheslav. Computational Modeling of Passenger Amphibian Aircraft Be-200 Cabin Interior. Advances in Engineering Software Vol. 76 (2014), p. 154-160.

[3] F Nicolosi, P Della Vecchia, S Corcione. Design and Aerodynamic Analysis of A Twin-Engine Commuter Aircraft. Aerospace Science and Technology Vol. 40 (2015), p. 1-16. 
[4] E R Galea, M Togher, P Lawrence. Investigating the Impact of Aircraft Exit Availability On Egress Time Using Computer Simulation, Springer Berlin Heidelberg (2010), p. 411-423.

[5] X J Han, X F Ding, C Xiao. The Research of Particle Swarm Algorithm Based On Heuristic Rules for the Layout of Airplane Equipment Cabin. Applied Mechanics and Materials Vol. 300 (2013), p. 659-663.

[6] J Smith, N Mansfield, D Gyi, et al. Driving Performance and Driver Discomfort in An Elevated and Standard Driving Position During A Driving Simulation. Applied Ergonomics Vol. 49 (2015), p. 25-33.

[7] Y L Wang, C Wang, Y Lin. Ship Cabin Layout Optimization Design Based On the Improved Genetic Algorithm Method. Applied Mechanics and Materials Vol. 300 (2013), p. 146-149.

[8] L Deng, G Wang, B Chen. Operating Comfort Prediction Model of Human-Machine Interface Layout for Cabin Based on GEP. Computational Intelligence \& Neuroscience (2015), p. 1-13.

[9] B Y Chung, S Y Kim, S C Shin, et al. Optimization of Compartments Arrangement of Submarine Pressure Hull with Knowledge Based System. International Journal of Naval Architecture \& Ocean Engineering Vol. 04 (2011), p. 254-262.

[10]X Luo, Y Yang, Z Ge, et al. Maintainability-Based Facility Layout Optimum Design of Ship Cabin. International Journal of Production Research Vol. 53 (2015), p. 677-694.

[11]M Bai, D M Zhuang, L Zhang, R Wang. Aircraft Operating Equipment layout optimization. Journal of Civil Aviation Flight University of China (2010), p. 28-31.

[12]K A Dowsland, W B Dowsland. Packing Problems. European Journal of Operational Research Vol. 56 (1992), p. 2-14.

[13]GJB2873-97. Human Engineering Design Criteria for Military Equipment and Facilities. Beijing: Chinese Pla General Armament Department, (1997).

[14]GJB36A-2008. Design and Requirements for the Templates of Human Body. Beijing: Chinese Pla General Armament Department, (2008). 